\title{
Extended x-ray absorption fine structure study of porous GaSb formed by ion implantation
}

\author{
P. Kluth, ${ }^{1}$ S. M. Kluth, ${ }^{1}$ B. Johannessen, ${ }^{2}$ C. J. Glover, ${ }^{2}$ G. J. Foran, ${ }^{2}$ and M. C. Ridgway ${ }^{1}$ \\ ${ }^{1}$ Department of Electronic Materials Engineering, Research School of Physics and Engineering, \\ The Australian National University, Canberra ACT 0200, Australia \\ ${ }^{2}$ Australian Synchrotron, 800 Blackburn Road, Clayton VIC 3168, Australia
}

(Received 21 April 2011; accepted 2 November 2011; published online 14 December 2011)

\begin{abstract}
Porous GaSb has been formed by Ga ion implantation into crystalline GaSb substrates at either room temperature or $-180{ }^{\circ} \mathrm{C}$. The morphology has been characterized using scanning electron microscopy and the atomic structure was determined using extended x-ray absorption fine structure spectroscopy. Room-temperature implantation at low fluences leads to the formation of $\sim 20-\mathrm{nm}$ voids though the material remains crystalline. Higher fluences cause the microstructure to evolve into a network of amorphous GaSb rods $\sim 15 \mathrm{~nm}$ in diameter. In contrast, implantation at $-180{ }^{\circ} \mathrm{C}$ generates large, elongated voids but no rods. Upon exposure to air, the surface of the porous material is readily oxidized yielding $\mathrm{Ga}_{2} \mathrm{O}_{3}$ and metallic $\mathrm{Sb}$ precipitates, the latter resulting from the reduction of unstable $\mathrm{Sb}_{2} \mathrm{O}_{3}$. We consider and discuss the atomic-scale mechanisms potentially operative during the concurrent crystalline-to-amorphous and continuous-to-porous transformations. (C) 2011 American Institute of Physics. [doi:10.1063/1.3665643]
\end{abstract}

\section{INTRODUCTION}

GaSb is a direct bandgap semiconductor suitable for fabricating high-frequency electronic devices and optoelectronic devices operating in the 2 - to 4 - $\mu$ m-wavelength range. ${ }^{1}$ Ion implantation, commonly used for device fabrication, can lead to the amorphization of crystalline semiconductor substrates. In addition, $\mathrm{GaSb}$ can also be rendered porous with the appropriate implant conditions. ${ }^{2,3} \mathrm{We}$ have previously reported on the fascinating variety of nanostructures (ranging from voids to an extensive network of rods) that can be generated by extending this phenomenon to higher implant fluences. ${ }^{4}$ The implant temperature was also shown to significantly influence the porous material morphology. Our interest in porous $\mathrm{GaSb}$ stems from this ability to tailor the pore morphology by altering the implant conditions with potential technological applications that include catalytic and optical devices.

Extended x-ray absorption fine structure (EXAFS) spectroscopy is a highly effective technique for characterization of ion-implantation-induced structural changes 5 in both elemental $\left(\mathrm{Si}^{6}{ }^{6} \mathrm{Ge}\right.$ (Refs. 7 and 8)) and binary $\left(\mathrm{Ge}_{x} \mathrm{Si}_{1-x},{ }^{9} \mathrm{GaP},{ }^{10}\right.$ GaAs, ${ }^{11}$ InP, ${ }^{12-14}$ and InAs (Ref. 15)) semiconductors. In general, amorphization yields structural disorder in the form of both bond-length and bond-angle distortions. In the III-V semiconductors, this can be accompanied by chemical disorder manifested as homopolar (like-atom) bonding in the amorphous phase. GaSb is well suited for an EXAFS study as the $K$-edges of both components are readily accessible and well separated in energy. Furthermore, the different photoelectron scattering strengths of $\mathrm{Ga}$ and $\mathrm{Sb}$ make the two components (and, hence, homopolar bonding) easily distinguishable.

In this paper, we correlate scanning electron microscopy (SEM) and EXAFS measurements to examine the morphology and atomic scale structure of porous $\mathrm{GaSb}$ formed by ion implantation. Both the implant fluence and temperature have been varied to produce porous material with a variety of morphologies. We show that voids are initially formed in crystalline material, whereas further implantation leads to the simultaneous evolution of the porous structure and amorphization. Using both SEM and EXAFS we are thus able to independently characterize the concurrent amorphous-tocrystalline and continuous-to-porous transformations.

\section{EXPERIMENTAL}

Multiple-energy, multiple-fluence ${ }^{69}$ Ga-ion-implantation sequences with energies ranging between 0.3 and $6.5 \mathrm{MeV}$ were performed under high vacuum into crystalline $\mathrm{GaSb}(100)$ substrates maintained at either room temperature (RT) or $-180{ }^{\circ} \mathrm{C}$. The stopping and range of ions in matter ${ }^{16}$ (SRIM) simulations were used to determine the appropriate fluences required to produce a uniform, athermal implantation-induced vacancy concentration to a depth of approximately $2.5 \mu \mathrm{m}$. The fluence/temperature combinations are listed in Table I. In all cases, the fluences were sufficient to induce porosity. All implant sequences were multiples of the lowest fluence sequence. For clarity hereafter, the samples will be referred to by the ion fluence for the highest-energy $(6.5 \mathrm{MeV})$ implant. We note that even at the highest implant fluence, the maximum deviation from stoichiometry caused by the implantation of $\mathrm{Ga}$ was negligible $(\sim 0.2$ at. $\%)$.

The morphology of the implanted material was examined using SEM performed on cleaved cross sections, whereas the atomic scale structure was determined with EXAFS. For the latter, the porous material was removed from the underlying substrate either mechanically (low implant fluences) or ultrasonically (high implant fluences), suspended in ethanol and subsequently vacuum filtered through a polyvinylidene fluoride membrane, then encapsulated with Kapton tape. An unimplanted, crystalline GaSb standard was produced by finely crushing a GaSb substrate and mixing with a BN binder. Ga and $\mathrm{Sb}$ metals were mechanically rolled to an appropriate thickness, 
TABLE I. ${ }^{69} \mathrm{Ga}$ implant fluences (in $\mathrm{cm}^{-2}$ ) for the multiple-energy implant sequences.

\begin{tabular}{lccccc}
\hline \hline \multicolumn{5}{c}{ Energy } & \\
\cline { 1 - 4 } $6.5 \mathrm{MeV}$ & $3.4 \mathrm{MeV}$ & $1.8 \mathrm{MeV}$ & $0.8 \mathrm{MeV}$ & $0.3 \mathrm{MeV}$ & \\
\cline { 1 - 5 } & Temperature \\
\hline $1 \times 10^{16}$ & $3.4 \times 10^{15}$ & $2.7 \times 10^{15}$ & $1.7 \times 10^{15}$ & $1.8 \times 10^{15}$ & $\mathrm{RT}$ \\
$1 \times 10^{16}$ & $3.4 \times 10^{15}$ & $2.7 \times 10^{15}$ & $1.7 \times 10^{15}$ & $1.8 \times 10^{15}$ & $-180{ }^{\circ} \mathrm{C}$ \\
$5 \times 10^{15}$ & $1.7 \times 10^{15}$ & $1.4 \times 10^{15}$ & $8.5 \times 10^{14}$ & $9.0 \times 10^{14}$ & $\mathrm{RT}$ \\
$5 \times 10^{15}$ & $1.7 \times 10^{15}$ & $1.4 \times 10^{15}$ & $8.5 \times 10^{14}$ & $9.0 \times 10^{14}$ & $-180^{\circ} \mathrm{C}$ \\
$2.5 \times 10^{15}$ & $8.5 \times 10^{14}$ & $7.0 \times 10^{14}$ & $4.3 \times 10^{14}$ & $4.5 \times 10^{14}$ & $-180^{\circ} \mathrm{C}$ \\
$2.5 \times 10^{15}$ & $8.5 \times 10^{14}$ & $7.0 \times 10^{14}$ & $4.3 \times 10^{14}$ & $4.5 \times 10^{14}$ & $\mathrm{RT}$ \\
$1 \times 10^{15}$ & $3.4 \times 10^{14}$ & $2.7 \times 10^{14}$ & $1.7 \times 10^{14}$ & $1.8 \times 10^{14}$ & $\mathrm{RT}$ \\
$5 \times 10^{14}$ & $1.7 \times 10^{14}$ & $1.4 \times 10^{14}$ & $8.5 \times 10^{14}$ & $9.0 \times 10^{13}$ & $\mathrm{RT}$ \\
$2.5 \times 10^{14}$ & $8.5 \times 10^{13}$ & $7.0 \times 10^{13}$ & $4.3 \times 10^{13}$ & $4.5 \times 10^{13}$ & $\mathrm{RT}$ \\
\hline \hline
\end{tabular}

and commercially available $\mathrm{Ga}_{2} \mathrm{O}_{3}$ was mixed with $\mathrm{BN}$ to generate metallic and oxide standards, respectively. All samples were fabricated such that $\mu x=\sim 1$, where $\mu$ is the absorption coefficient and $x$ is the effective thickness of the material.

Transmission EXAFS measurements were performed at the Australian National Beamline Facility, beamline 20B, at the Photon Factory, Japan. Data was collected at both the Ga $(10.367 \mathrm{keV})$ and $\mathrm{Sb}(30.491 \mathrm{keV}) K$-edges. All measurements were performed at a temperature of $\sim 20 \mathrm{~K}$ to minimize thermal vibrations.

EXAFS analysis was performed using the software code IFEFFIT, ${ }^{17,18}$ in combination with FEFF6, $^{19}$ for multiparametric, non-linear least-squares fitting of the first coordination shell. Isolated EXAFS spectra were Fourier transformed over photoelectron wavenumber $k$ ranges of $4-17.5 \AA^{-1}$ and 5.3-16 $\AA^{-1}$ for the Ga and Sb edges, respectively. To isolate the first-nearest-neighbor scattering contributions, $r$-space windows of 1.8-3.0 $\AA$ and 1.8-3.3 $\AA$ were utilized at the Ga and $\mathrm{Sb}$ edges, respectively, where $r$ is the non-phase-corrected radial distance. The wider window at the $\mathrm{Sb}$ edge was used to simultaneously encompass the scattering contributions from $\mathrm{Ga}$ and potentially $\mathrm{Sb}$ nearest neighbors, the latter a result of the presence of $\mathrm{Sb}-\mathrm{Sb}$ bonding in metallic $\mathrm{Sb}$ and/or amorphous GaSb. Fitting was performed in $r$ space. The amplitudereduction factor $\left(\mathrm{SO}_{2}\right)$ and threshold energy $\left(E_{0}\right)$ were determined from either the crystalline $\mathrm{GaSb}$ or metallic Sb standards as appropriate. The structural parameters of the $\mathrm{Ga}-\mathrm{Sb}$ bond (the bond length, Debye-Waller factor, and coordination number) were determined from simultaneously fitting the spectra from both the $\mathrm{Ga}$ and $\mathrm{Sb}$ edges. The $\mathrm{Sb}-\mathrm{Sb}$ contribution, apparent in the Sb-edge spectra for implantation fluences of $5 \times 10^{14} \mathrm{~cm}^{-2}$ and beyond, was included by adding the first shell scattering path from the $\mathrm{Sb}$ metal with floating bond length and coordination number. The Debye-Waller factor of the $\mathrm{Sb}-\mathrm{Sb}$ contribution in the mixed shell was constrained to that obtained from a fit to the $\mathrm{Sb}$ metal spectrum, because of the high correlation with the $\mathrm{Sb}-\mathrm{Sb}$ coordination number, to achieve a meaningful analysis.

\section{RESULTS}

\section{Morphology: SEM}

Figure 1 shows cross-sectional SEM images of the microstructure for the various implant conditions. Following
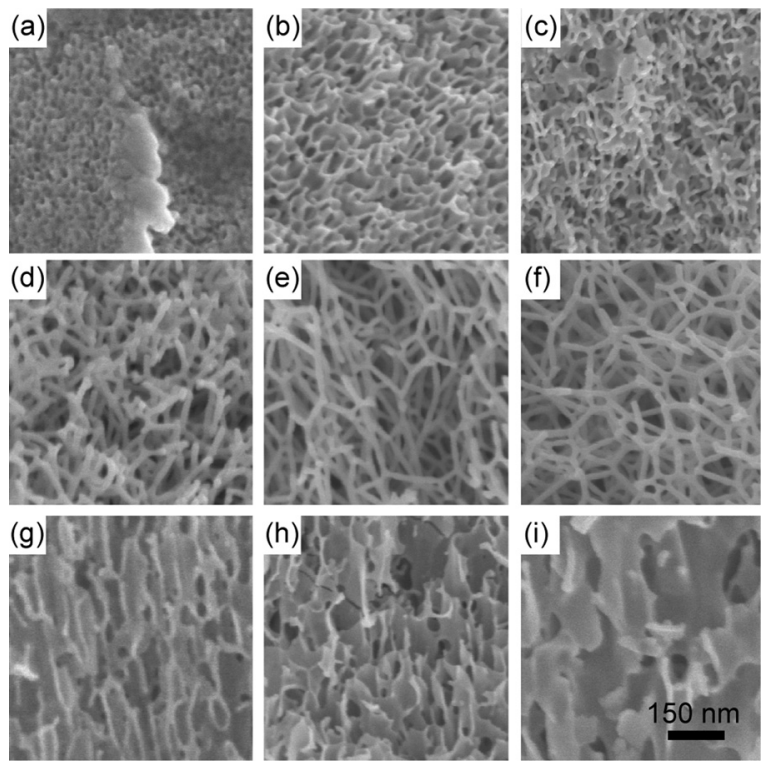

FIG. 1. Cross-sectional SEM images of samples implanted at room temperature: (a) $2.5 \times 10^{14} \mathrm{~cm}^{-2}$, (b) $5 \times 10^{14} \mathrm{~cm}^{-2}$, (c) $1 \times 10^{15} \mathrm{~cm}^{-2}$, (d) $2.5 \times 10^{15} \mathrm{~cm}^{-2}$, (e) $5 \times 10^{15} \mathrm{~cm}^{-2}$, and (f) $1 \times 10^{16} \mathrm{~cm}^{-2}$; and samples implanted at $-180{ }^{\circ} \mathrm{C}$ : (g) $2.5 \times 10^{15} \mathrm{~cm}^{-2}$, (h) $5 \times 10^{15} \mathrm{~cm}^{-2}$, and (i) $1 \times 10^{16} \mathrm{~cm}^{-2}$.

the lowest fluence $\left(2.5 \times 10^{14} \mathrm{~cm}^{-2}\right)$ implantation at room temperature, voids $\sim 20 \mathrm{~nm}$ in diameter are apparent throughout the implanted region (Fig. 1(a)). The voids become larger and elongated by $5 \times 10^{14} \mathrm{~cm}^{-2}$ (Fig. 1(b)), whereas increasing the fluence further to $1 \times 10^{15} \mathrm{~cm}^{-2}$ causes the material to evolve into a plate-like configuration (Fig. 1(c)) as a more open structure develops. The plates are $\sim 15$-nm thick and are joined by rods of similar thickness. Fluences of $2.5 \times 10^{15} \mathrm{~cm}^{-2}$ and beyond (Figs. 1(d)-1(f)) result in a network of $\sim 15$-nm-diameter rods. No further evolution of the microstructure was apparent above this fluence, although the overall thickness of the porous layer continued to increase, potentially the result of incident ions penetrating the now open structure to reach the previously unirradiated underlying substrate. As the porous morphology did not change observably over the depth of the implanted layer in each sample, it can be concluded that the ion energy has no direct influence on the porous microstructure.

Reducing the implant temperature to $-180{ }^{\circ} \mathrm{C}$ yields a markedly different microstructure to that formed at room temperature (Figs. 1(g)-1(i)). The overall porous layer thickness is a factor of four lower than for similar implants at room temperature and even following the highest fluence implantation there is no evidence of rod formation. Instead, long, columnar void-like structures with discontinuous walls of thickness $\sim 10 \mathrm{~nm}$ are observed as consistent with the observations of Nitta et al. ${ }^{3}$ As we described previously, ${ }^{4}$ the general microstructural evolution is attributable to the precipitation of implantation-induced interstitials at extended defects in preference to Frenkel pair recombination. The temperature-dependent minimum feature size is an indirect measurement of vacancy mobility. If vacancies cannot reach the plate or rod surface where they are annihilated, they agglomerate, form voids, and the porous structure continues to evolve. 


\section{Microstructure: EXAFS and XANES}

For room-temperature implantation, $k^{3}$-weighted EXAFS spectra recorded at the $\mathrm{Ga}$ and $\mathrm{Sb} K$-edges are shown in Figs. 2(a) and 3(a), respectively, as a function of the photoelectron wavenumber $k$. At both edges, the highly structured EXAFS oscillations of the crystalline standard are washed out with increasing fluence, the decrease in amplitude consistent with the introduction of implantation-induced disorder, and the loss of long-range order. A clear change in the Ga-edge spectra below $k=\sim 6 \AA^{-1}$ is apparent once the implant fluence

(a)

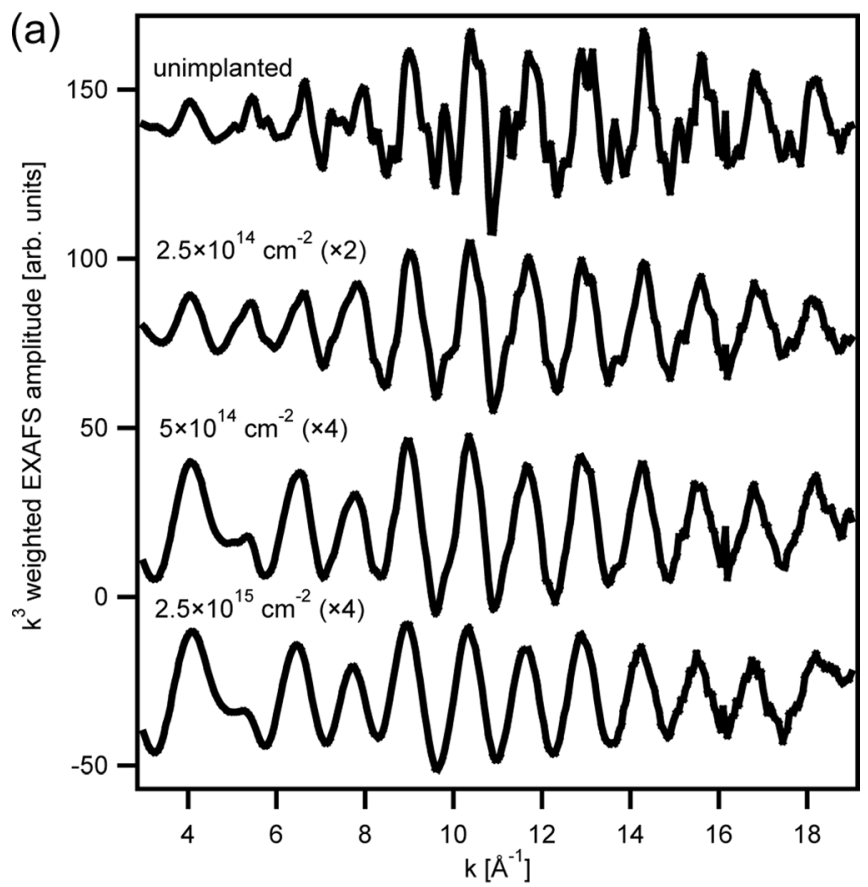

(b)

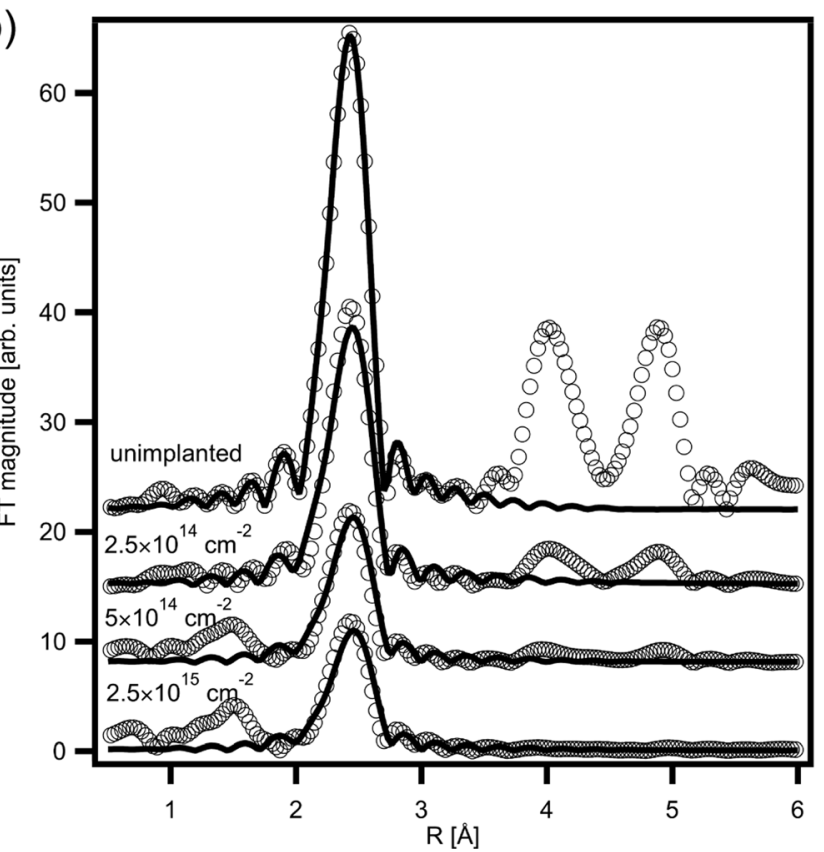

FIG. 2. (a) $k^{3}$-weighted EXAFS spectra of GaSb recorded at the Ga $K$ edge vs the photoelectron wavenumber $k$ for various implant fluences at room temperature. (Note: The amplitude of all but the unimplanted spectrum has been scaled by the factors indicated in the figure.) (b) Corresponding Fourier transforms as a function of the non-phase-corrected radial distance $R$ from the absorber (symbols) and fits (solid lines).
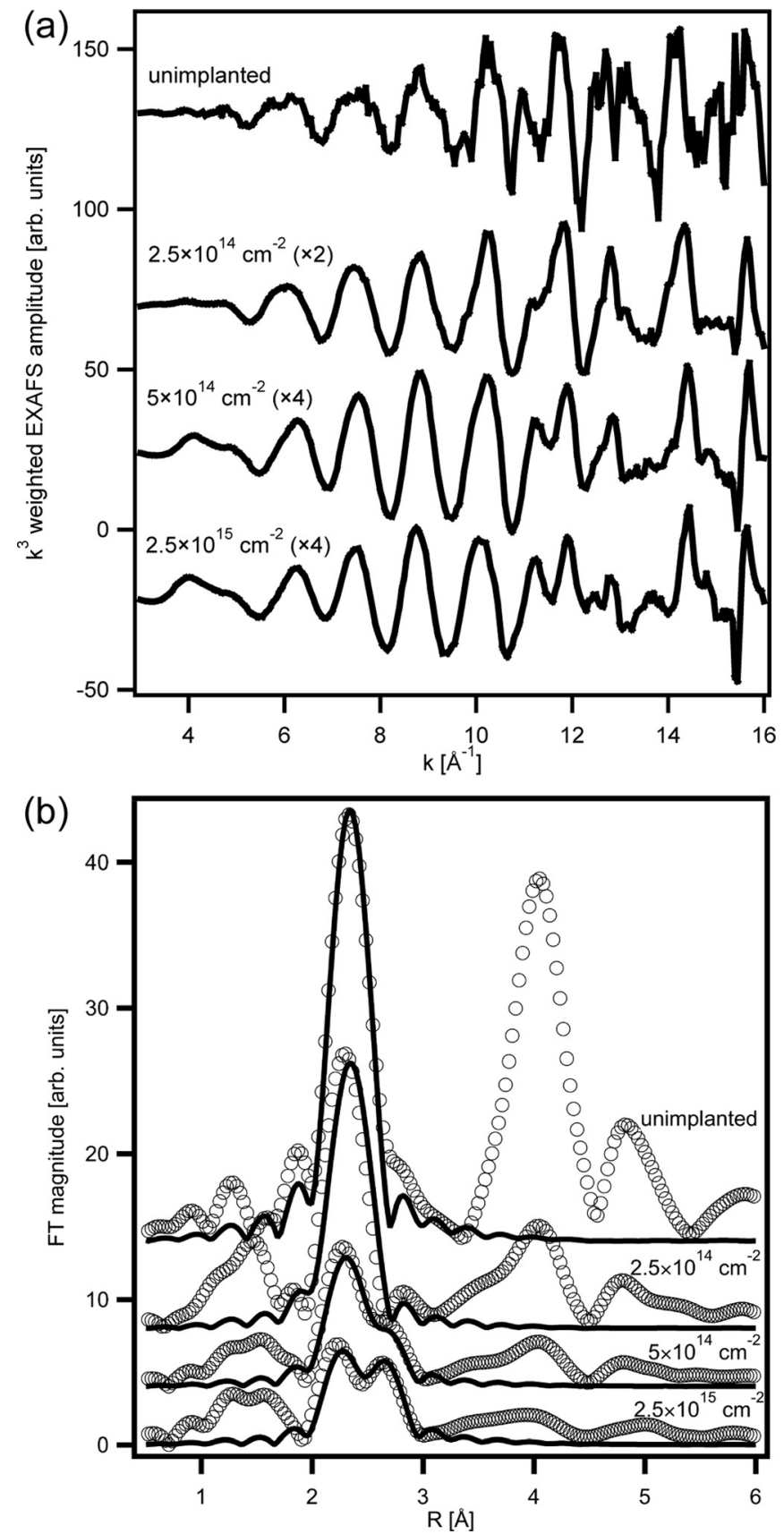

FIG. 3. (a) $k^{3}$-weighted EXAFS spectra of GaSb recorded at the $\mathrm{Sb} K$ edge vs the photoelectron wavenumber $k$ for various implant fluences at room temperetaure. (Note: The amplitude of all but the unimplanted spectrum has been scaled by the factors indicated in the figure.) (b) Corresponding Fourier transforms as a function of the non-phase-corrected radial distance $R$ from the absorber (symbols) and fits (solid lines).

exceeds $5 \times 10^{14} \mathrm{~cm}^{-2}$ as a result of, as described below, Ga oxide formation.

Fourier-transformed spectra and the corresponding fits are shown in Figs. 2(b) and 3(b) as a function of the nonphase-corrected radial distance $r$ for the $\mathrm{Ga}$ and $\mathrm{Sb}$ edges, respectively. For the crystalline standard, the three prominent peaks below $r=\sim 5 \AA$ are characteristic of the three nearest neighbors in the zinc-blende structure. At the Ga edge, these are $4 \mathrm{Sb}$ atoms at $2.649 \AA, 12 \mathrm{Ga}$ atoms at $4.326 \AA$, and $12 \mathrm{Sb}$ atoms at $5.073 \AA$. At the Sb edge, the distances are the same but the Ga and Sb scattering atoms are 
TABLE II. Refined fitting parameters from EXAFS analysis of the first coordination shell as a function of ion irradiation fluence. $N, r$, and $\sigma^{2}$ are the coordination number, bond length, and Debye-Waller factor, respectively.

\begin{tabular}{|c|c|c|c|c|c|c|c|}
\hline \multirow[b]{2}{*}{ Fluence $\left(\mathrm{cm}^{-2}\right)$} & \multirow[b]{2}{*}{$T\left({ }^{\circ} \mathrm{C}\right)$} & \multicolumn{3}{|c|}{$\mathrm{Ga}-\mathrm{Sb}$} & \multicolumn{3}{|c|}{$\mathrm{Sb}-\mathrm{Sb}$} \\
\hline & & $N$ & $r(\AA)$ & $\sigma^{2}\left(10^{-3} \AA^{2}\right)$ & $N$ & $r(\AA)$ & $\sigma^{2}\left(10^{-3} \AA^{2}\right)$ \\
\hline $1 \times 10^{16}$ & RT & $1.6 \pm 0.2$ & $2.654 \pm 0.003$ & $4.0 \pm 0.5$ & $0.8 \pm 0.2$ & $2.861 \pm 0.008$ & 1.1 (set) \\
\hline $1 \times 10^{16}$ & -180 & $1.6 \pm 0.2$ & $2.656 \pm 0.003$ & $4.0 \pm 0.5$ & $0.7 \pm 0.4$ & $2.880 \pm 0.015$ & 1.1 (set) \\
\hline $5 \times 10^{15}$ & $\mathrm{RT}$ & $1.7 \pm 0.2$ & $2.655 \pm 0.002$ & $3.9 \pm 0.5$ & $0.9 \pm 0.5$ & $2.880 \pm 0.008$ & 1.1 (set) \\
\hline $2.5 \times 10^{15}$ & $\mathrm{RT}$ & $1.8 \pm 0.2$ & $2.654 \pm 0.002$ & $4.0 \pm 0.5$ & $0.8 \pm 0.2$ & $2.866 \pm 0.007$ & 1.1 (set) \\
\hline $2.5 \times 10^{15}$ & -180 & $1.5 \pm 0.2$ & $2.656 \pm 0.003$ & $3.8 \pm 0.6$ & $0.8 \pm 0.3$ & $2.870 \pm 0.009$ & 1.1 (set) \\
\hline $1 \times 10^{15}$ & $\mathrm{RT}$ & $1.6 \pm 0.3$ & $2.655 \pm 0.004$ & $4.3 \pm 0.7$ & $0.9 \pm 0.1$ & $2.861 \pm 0.006$ & 1.1 (set) \\
\hline $5 \times 10^{14}$ & RT & $2.1 \pm 0.3$ & $2.647 \pm 0.002$ & $4.0 \pm 0.5$ & $0.6 \pm 0.1$ & $2.865 \pm 0.009$ & 1.1 (set) \\
\hline $2.5 \times 10^{14}$ & $\mathrm{RT}$ & $3.4 \pm 0.3$ & $2.643 \pm 0.002$ & $3.6 \pm 0.3$ & NA & NA & NA \\
\hline Polycrystalline & NA & 4 (set) & $2.635 \pm 0.002$ & $2.3 \pm 0.2$ & NA & NA & NA \\
\hline
\end{tabular}

reversed leading to the different peak heights apparent in the spectra. Implantation-induced disorder causes the scattering contribution from the second and third nearest neighbors to decrease with fluence until they are no longer discernable at a fluence of $2.5 \times 10^{15} \mathrm{~cm}^{-2}$, consistent with complete amorphization. Disorder also yields the decrease in height and increase in width of the first-nearest-neighbor peak. Additional peaks become apparent in the $\mathrm{Ga}$ and $\mathrm{Sb}$ spectra at $r=\sim 1.5 \AA$ and $\sim 2.65 \AA$, respectively, for fluences in excess of $5 \times 10^{14} \mathrm{~cm}^{-2}$. As discussed later, these scattering contributions result from the formation of $\mathrm{Ga}$ oxide $(\mathrm{Ga}$ spectrum) and $\mathrm{Sb}-\mathrm{Sb}$ bonding ( $\mathrm{Sb}$ spectrum) in metallic $\mathrm{Sb}$ and/or amorphous GaSb. The refined fitting parameters are listed in Table II. The errors correspond to the uncertainties from the non-linear least-squares fits.

Significant changes in the Ga-edge $\mathrm{x}$-ray absorption near-edge structure (XANES) were also apparent as shown in Fig. 4(a) as a function of implant fluence. Figure 4(b) compares the XANES spectra of material implanted to a fluence of $1 \times 10^{16} \mathrm{~cm}^{-2}$ with a linear combination of the $\mathrm{GaSb}$ and $\mathrm{Ga}_{2} \mathrm{O}_{3}$ standard spectra. By varying the weighting of the two standards, the implanted material spectra could be readily reproduced and thus the oxide fraction easily quantified. The fraction of $\mathrm{Ga}$ atoms in $\mathrm{Ga}_{2} \mathrm{O}_{3}$ is shown in Fig. 4(c) as a function of implant fluence.

\section{DISCUSSION}

The structural parameters derived from the EXAFS measurements are listed in Table II. Clearly, as evident from Fig. 2(b), the crystalline-to-amorphous phase transformation is complete for an implant fluence of $2.5 \times 10^{15} \mathrm{~cm}^{-2}$. For the material implanted at room temperature with the highest fluence $\left(1 \times 10^{16} \mathrm{~cm}^{-2}\right)$, the Ga-Sb Debye-Waller factor $\left(0.0040 \pm 0.0005 \AA^{2}\right)$ is approximately double the crystalline value $\left(0.0023 \pm 0.0001 \AA^{2}\right)$ indicative of the considerable structural disorder present in the amorphous phase. Figure 5(a) shows the Ga-Sb bond length as a function of implant fluence. The bond length increases from the crystalline value of $2.635 \AA$ until it saturates at $\sim 2.655 \AA$. The increases in both Debye-Waller factor and bond length are consistent with observations for other III-V semiconductors rendered amorphous by ion implantation. ${ }^{5,20}$ (Note that while we observed residual GaSb crystallites with transmission electron microscopy even for the highest implant fluence, ${ }^{4}$ their relative fraction must be minimal given the lack of secondnearest-neighbor scattering contributions in the EXAFS spectra.)

The Ga-Sb coordination number is plotted as a function of implant fluence in Fig. 5(b). Clearly, the number of Sb atoms surrounding a Ga absorber decreases dramatically as a function of the implant fluence, the onset of porosity, and oxidation of the porous-material surface. The oxidized fraction saturates at $\sim 55 \%$ for implant fluences of $\sim 1 \times 10^{15} \mathrm{~cm}^{-2}$ and beyond, presumably correlated with a saturation of the porous-material surface area. A slight decrease $(\sim 10 \%)$ in the heteropolar coordination number is common for amorphized III-V semiconductors because of the presence of both threefold-coordinated defect structures and homopolar bonding. ${ }^{20}$ In the present report, the much greater decrease in heteropolar coordination number is the result of the additional and dominant influence of oxide formation.

Excluding the lowest implant fluence, an unusually large fraction of $\mathrm{Sb}-\mathrm{Sb}$ bonding is also present following implantation with the $\mathrm{Sb}-\mathrm{Sb}$ coordination number saturating at a value of $\sim 1$ for implant fluences of $1 \times 10^{15} \mathrm{~cm}^{-2}$ and beyond, as shown in Fig. 6(a). Clearly, a significant fraction of $\mathrm{Sb}$ atoms are involved in such bonding. As apparent from Fig. $6(\mathrm{~b})$, the $\mathrm{Sb}-\mathrm{Sb}$ bond length exhibits an average value of $2.869 \AA, \sim 1 \%$ shorter than metallic Sb, with no observable trend.

Figure 4(c) demonstrates that the $\mathrm{Ga}_{2} \mathrm{O}_{3}$ fraction increases with increasing implant fluence, saturating at $~ 55 \%$ for $1 \times 10^{15} \mathrm{~cm}^{-2}$ and beyond. The extremely large oxide fraction is consistent with the high reactivity of the GaSb surface. Though a native oxide is typically observed on wafer surfaces, the much enhanced surface-area-to-volume ratio of the porous structure yields the enormous increase in oxide fraction relative to bulk material. Using transmission electron microscopy, an O-rich, amorphous layer of thickness $\sim 2-3$ $\mathrm{nm}$ was apparent on the porous-material surface ${ }^{21}$ as consistent with a surface oxide. Approximating the structure as 15 -nm-diameter rods including a $2.5 \mathrm{~nm}$ thick surface oxide yields $56 \%$ oxide by volume and agrees well with the XANES data presented above. 

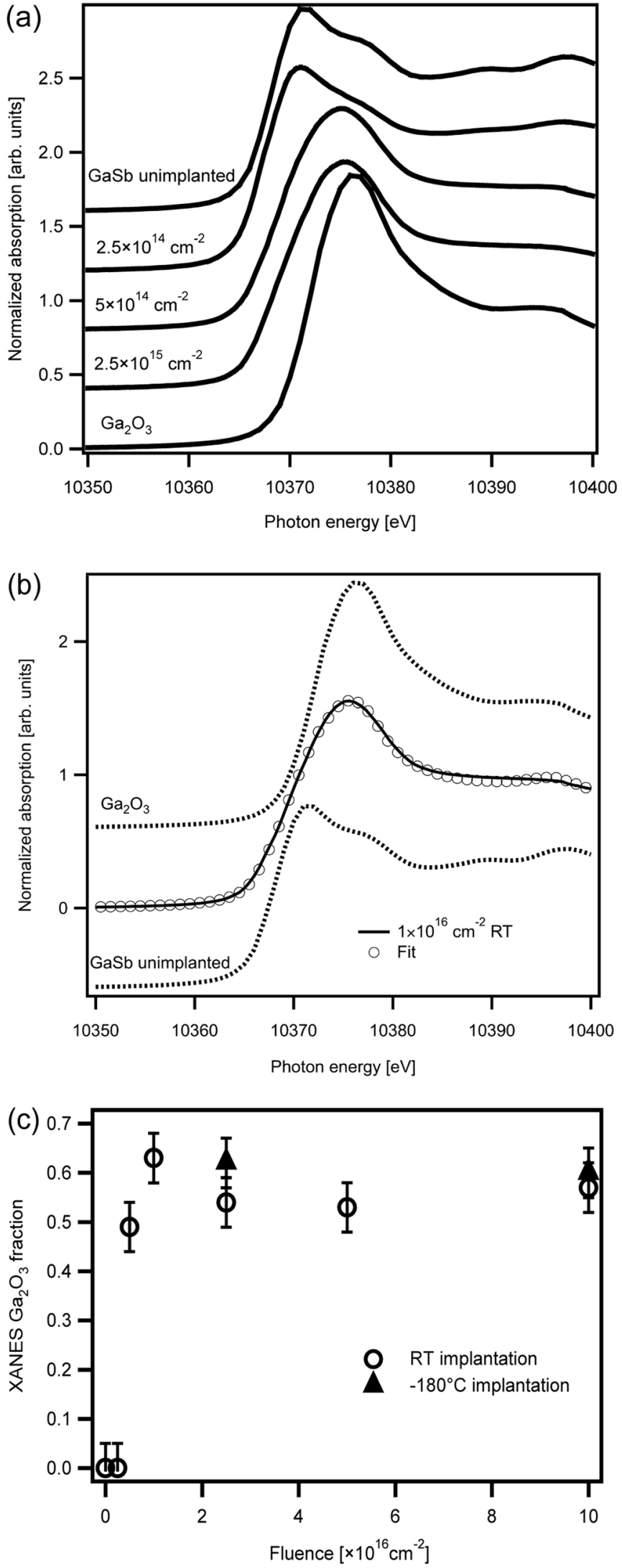

FIG. 4. (a) Normalized XANES spectra recorded at the Ga $K$ edge for $\mathrm{Ga}_{2} \mathrm{O}_{3}$ and $\mathrm{GaSb}$ for various implant fluences at room temperature. (b) XANES spectrum of GaSb implanted with $1 \times 10^{16} \mathrm{~cm}^{-2}$ at room temperature (lines) and linear combination fit using the unimplanted $\mathrm{GaSb}$ and $\mathrm{Ga}_{2} \mathrm{O}_{3}$ spectra (symbols). The dashed lines show the spectra of unimplanted $\mathrm{GaSb}$ and $\mathrm{Ga}_{2} \mathrm{O}_{3}$. (c) $\mathrm{Ga}_{2} \mathrm{O}_{3}$ fraction as a function of implantation fluence for irradiation at room temperature and at $-180^{\circ} \mathrm{C}$.

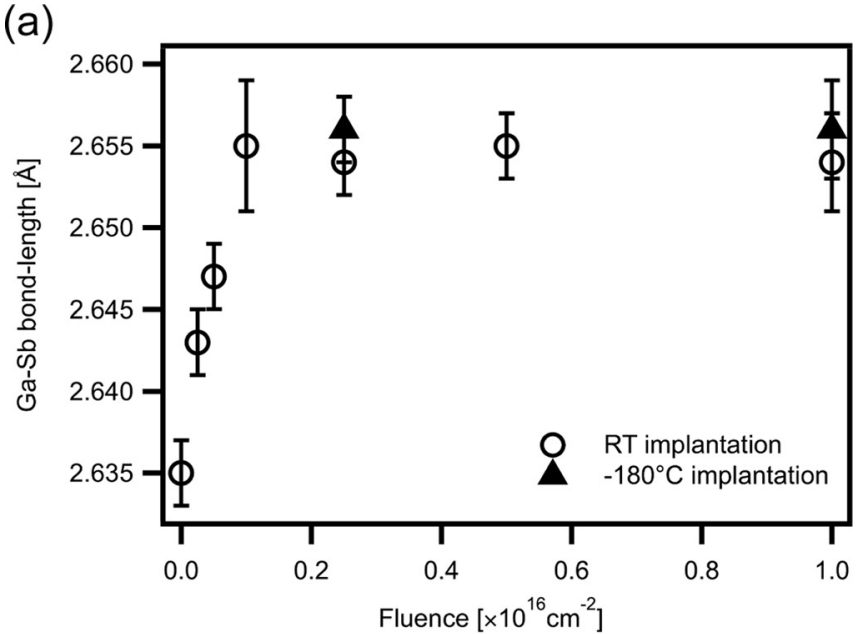

(b) 40

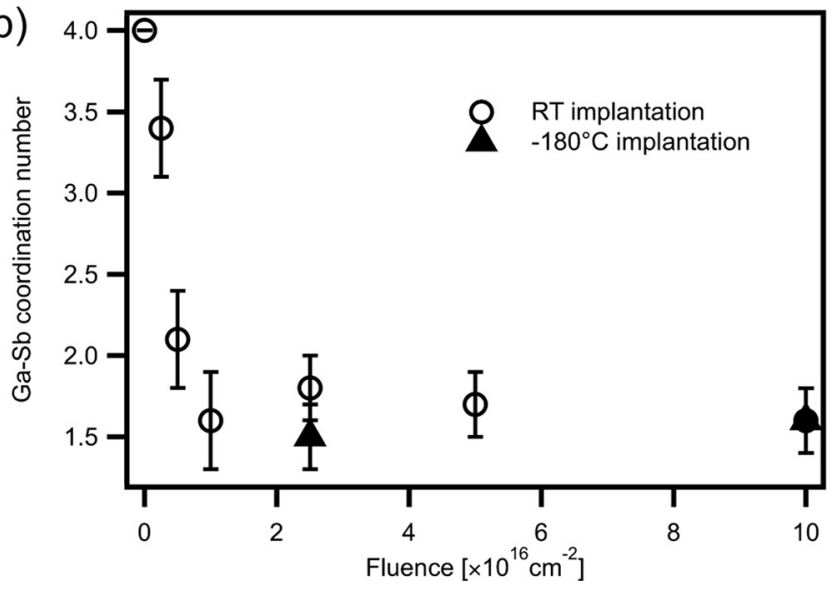

FIG. 5. (a) Ga-Sb bond length, and (b) Ga-Sb coordination number as a function of implantation fluence.

The formation of native oxides on the GaSb surface occurs at low temperature by the reaction:

$$
2 \mathrm{GaSb}+3 \mathrm{O}_{2} \rightarrow \mathrm{Ga}_{2} \mathrm{O}_{3}+\mathrm{Sb}_{2} \mathrm{O}_{3} .
$$

Thermodynamically, the only stable species that can coexist with $\mathrm{GaSb}$ are $\mathrm{Ga}_{2} \mathrm{O}_{3}$ and elemental $\mathrm{Sb}$ as the $\mathrm{Sb}$ oxide phase is unstable on the $\mathrm{GaSb}$ surface. Sb oxide may subsequently react with $\mathrm{GaSb}$ to form $\mathrm{Ga}_{2} \mathrm{O}_{3}$ and elemental $\mathrm{Sb}$ at the oxide/antimonide interface through the reaction: ${ }^{22}$

$$
\mathrm{Sb}_{2} \mathrm{O}_{3}+2 \mathrm{GaSb} \rightarrow \mathrm{Ga}_{2} \mathrm{O}_{3}+4 \mathrm{Sb} .
$$

Kitamura et $a l .{ }^{23}$ found that a thermal oxide layer consisted almost entirely of $\mathrm{Ga}_{2} \mathrm{O}_{3}$ with a small amount of oxidized $\mathrm{Sb}$ at the oxide surface and a large amount of elemental $\mathrm{Sb}$ at the $\mathrm{Ga}_{2} \mathrm{O}_{3} / \mathrm{GaSb}$ interface. This explains both the large drop in the $\mathrm{Ga}-\mathrm{Sb}$ coordination number and the high fraction of $\mathrm{Sb}-\mathrm{Sb}$ bonds. Approximately half the $\mathrm{Ga}$ atoms are oxidized (i.e., bonded to $\mathrm{O}$ instead of $\mathrm{Sb}$ ) such that the average coordination number for the $\mathrm{Ga}-\mathrm{Sb}$ bond is approximately halved, whereas a fraction of $\mathrm{Sb}$ atoms are bonded to one another as excess metallic $\mathrm{Sb}$. We anticipate the latter are in the form of small clusters given the measured $\mathrm{Sb}-\mathrm{Sb}$ coordination number of $\sim 1$. Finite-size effects can reduce the coordination number measured in metal clusters/nanoparticles to values 

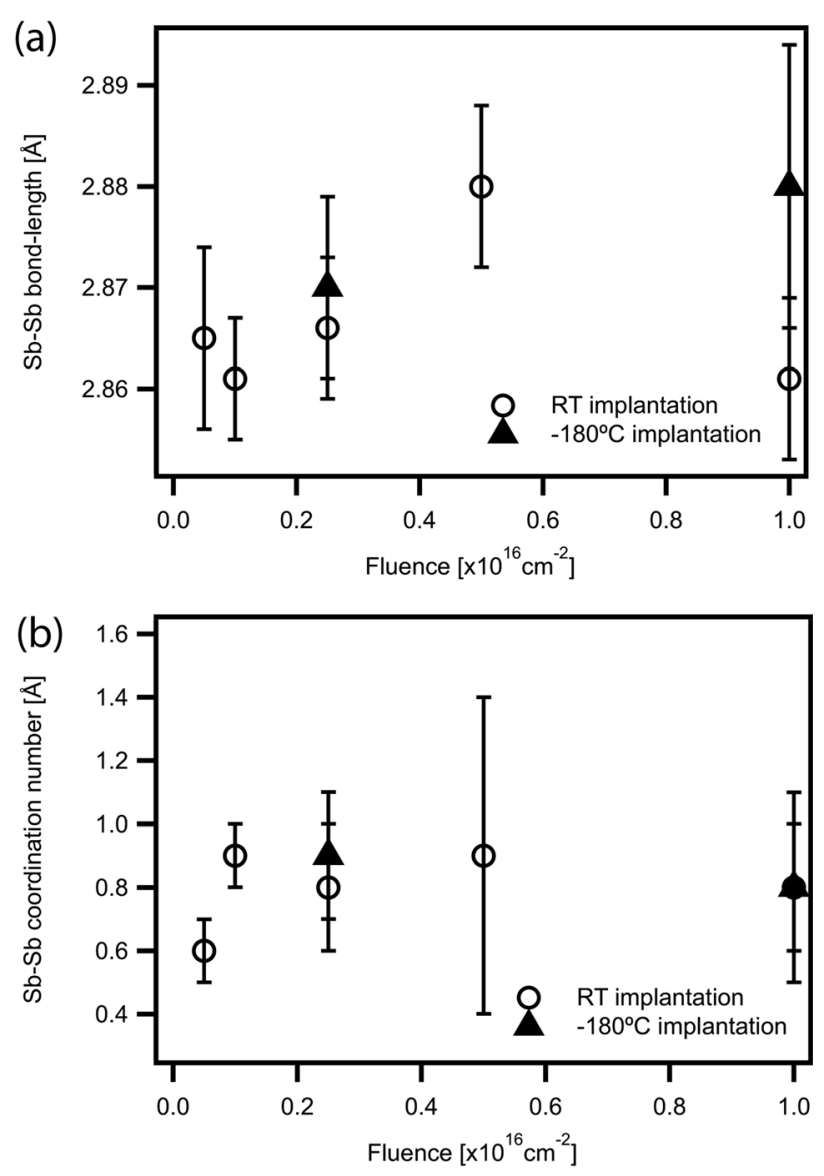

FIG. 6. (a) Sb-Sb bond length, and (b) $\mathrm{Sb}-\mathrm{Sb}$ coordination number as a function of implantation fluence.

less than those of bulk material, as widely reported for a variety of metals. ${ }^{24-27}$

Unfortunately, the considerable oxide fraction inhibits the quantification of homopolar bonding within the GaSb material. Whereas $\mathrm{Sb}-\mathrm{Sb}$ bonding is clearly detectable, one cannot quantify the relative fractions resulting from homopolar bonding within amorphous $\mathrm{GaSb}$ and from metallic $\mathrm{Sb}$ arising because of oxidation. Ga-Ga bonding, on the other hand, can be only attributed to homopolar bonding in amorphous GaSb. However, the Ga-Ga bond length in Ga metal $(2.437 \AA)$ is close to that of $\mathrm{Ga}-\mathrm{Sb}$ in amorphous $\mathrm{GaSb}$ (2.706 $\AA$ ). Whereas we see no evidence of homopolar $\mathrm{Ga}-\mathrm{Ga}$ bonding, such an observation is further impeded by the greater scattering strength of the heavier $\mathrm{Sb}$ atoms relative to that of the $\mathrm{Ga}$ atoms.

The $\mathrm{Ga}_{2} \mathrm{O}_{3}$ fraction appears to be independent of the sample morphology as it saturates for fluences between $5 \times 10^{14} \mathrm{~cm}^{-2}$ and $1 \times 10^{15} \mathrm{~cm}^{-2}$, whereas the structure continues to evolve up to $2.5 \times 10^{15} \mathrm{~cm}^{-2}$. Furthermore, the oxide content in the samples implanted at $-180{ }^{\circ} \mathrm{C}$ is similar to those implanted at room temperature despite the denser more cellular structure with an apparent lower surface area observed in these samples, possibly indicating that a selflimiting oxidation process may be operative. Whereas we cannot conclusively characterize the level of $\mathrm{Sb}$ oxide in the sample, it appears to be minor.

The $\mathrm{Ga}_{2} \mathrm{O}_{3}$ on the surface of the material highlights a potential application of these nanostructures. Among other applications, $\mathrm{Ga}_{2} \mathrm{O}_{3}$ is used as a catalyst. ${ }^{28}$ The enormous $\mathrm{Ga}_{2} \mathrm{O}_{3}$-surface-to-volume ratio provided by our structures would be ideal for catalytic applications where a large reaction surface is desired. For applications where the preservation of $\mathrm{GaSb}$ is required in the porous material, the deposition of a capping layer could be a means of avoiding oxidation when the samples are exposed to atmosphere conditions after irradiation.

For the lowest fluence $\left(2.5 \times 10^{14} \mathrm{~cm}^{-2}\right)$, where only small discontinuous voids are seen in Fig. 1(a), no oxide is apparent from the measurements. This is consistent with the findings of Callec et al. ${ }^{29}$ that the oxidation indeed occurs subsequent to the implantation once the sample is exposed to air. In the low-fluence samples, the void surfaces are fully enclosed and no oxidation occurs. The presence of secondnearest-neighbor peaks in Fig. 2(b) indicates that void formation is initiated in crystalline material not in amorphous material as is the case for Ge. ${ }^{30,31}$ Most of the structural evolution has occurred before the $\mathrm{GaSb}$ becomes amorphous $\left(\sim 2.5 \times 10^{15} \mathrm{~cm}^{-2}\right)$.

\section{CONCLUSIONS}

Ion implantation of $\mathrm{GaSb}$ causes the material to become highly porous. Initially, voids form in the crystalline material. With increasing implant fluence, the structure continues to evolve and the crystalline material is rendered amorphous. At room temperature, the fluence required for amorphization is similar to that needed for the formation of an open rodbased structure. At $-180{ }^{\circ} \mathrm{C}$, only large elongated voids are formed. Because of the high surface area of the structures, and a tendency to oxidize upon exposure to air, approximately half the implanted $\mathrm{GaSb}$ is converted to $\mathrm{Ga}_{2} \mathrm{O}_{3}$. Metallic $\mathrm{Sb}$ then results from the oxidation reaction. The residual GaSb exhibits similar structural parameters to other III-V semiconductors rendered amorphous by ion implantation including a doubling of the Debye-Waller factor and a bond-length expansion. Homopolar bonding of $\mathrm{Sb}$ atoms is observed but one cannot differentiate between that of metallic $\mathrm{Sb}$ and that in amorphous GaSb.

${ }^{1}$ P. S. Dutta, H. L. Bhat, and V. Kumar, J. Appl. Phys. 81, 5821 (1997).

${ }^{2}$ R. Callec and A. Poudoulec, J. Appl. Phys. 73, 4831 (1993).

${ }^{3}$ N. Nitta, M. Taniwaki, Y Hayashi, and T. Yoshiie, J. Appl. Phys. 92, 1799 (2002).

${ }^{4}$ S. M. Kluth, J. D. F. Gerald, and M. C. Ridgway, Appl. Phys. Lett. 86, 131920 (2005).

${ }^{5}$ M. C. Ridgway, C. J. Glover, G. de M. Azevedo, S. M. Kluth, K. M. Yu, and G. J. Foran, Nucl. Instrum. Methods Phys. Res. B 238, 294 (2005).

${ }^{6}$ C. J. Glover, G. J. Foran, and M. C. Ridgway, Nucl. Instrum. Methods Phys. Res. B 199, 195 (2003).

${ }^{7}$ M. C. Ridgway, C. J. Glover, K. M. Yu, G. J. Foran, C. Clerc, J. L. Hansen, and A. Nylandsted Larsen, Phys. Rev. B 61, 12586 (2000).

${ }^{8}$ C. J. Glover, M. C. Ridgway, K. M. Yu, G. J. Foran, D. Desnica-Frankovic, C. Clerc, J. L. Hansen, and A. Nylandsted-Larsen, Phys. Rev. B 63, 073204 (2001).

${ }^{9}$ M. C. Ridgway, K. M. Yu, C. J. Glover, G. J. Foren, C. Clerc, J. L. Hansen, and A. N. Larsen, Phys. Rev. B 60, 10831 (1999).

${ }^{10}$ M. C. Ridgway, S. E. Everett, C. J. Glover, S. M. Kluth, P. Kluth, B. Johannessen, Z. S. Hussain, D. J. Llewellyn, G. J. Foran, and G. de M. Azevedo, Nucl. Instrum. Methods Phys. Res. B 250, 287 (2006).

${ }^{11}$ M. C. Ridgway, C. J. Glover, G. J. Foran, and K. M. Yu, J. Appl. Phys. 83, 4610 (1998) 
${ }^{12}$ C. J. Glover, M. C. Ridgway, K. M. Yu, G. J. Foran, T. W. Lee, Y. Moon, and E. Yoon, Appl. Phys. Lett. 74, 1713 (1999).

${ }^{13}$ G. de M. Azevedo, C. J. Glover, M. C. Ridgway, K. M. Yu, and G. J. Foran, Phys. Rev. B 68, 115204 (2003).

${ }^{14}$ C. S. Schnohr, P. Kluth, A. P. Byrne, G. J. Foran, and M. C. Ridgway, Phys. Rev. B 77, 073204 (2008).

${ }^{15}$ G. de M. Azevedo, M. Ridgway, K. Yu, C. Glover, and G. Foran, Nucl. Instrum. Methods Phys. Res. B 190, 851 (2002).

${ }^{16}$ J. F. Ziegler, J. P. Biersack, and U. Littmark, The Stopping and Range of Ions in Matter (Pergamon, New York, 1985).

${ }^{17}$ M. Newville, J. Synchrotron Radiat. 8, 322 (2001).

${ }^{18}$ B. Ravel and M. Newville, J. Synchrotron Radiat. 12, 537 (2005).

${ }^{19}$ J. J. Rehr and R. C. Albers, Phys. Rev. B 41, 8139 (1990).

${ }^{20}$ M. C. Ridgway, G. de M. Azevedo, C. J. Glover, K. M. Yu, and G. J. Foran, Nucl. Instrum. Methods Phys. Res. B 199, 235 (2003).

${ }^{21}$ S. M. Kluth, B. Johannessen, P. Kluth, C. J. Glover, G. J. Foran, and M. C. Ridgway, Nucl. Instrum. Methods Phys. Res. B 238, 264 (2005).

${ }^{22}$ Z. Y. Liu, B. Hawkins, and T. F. Kuech, J. Vac. Sci. Technol. B 21, 71 (2003).
${ }^{23}$ N. Kitamura, M. Kakehi, J. Shen, and T. Wada, Jpn. J. Appl. Phys. 23, 1534 (1984)

${ }^{24}$ P. Kluth, B. Johannessen, V. Giraud, A. Cheung, C. J. Glover, G. de M. Azevedo, M. C. Ridgway, and G. J. Foran, Appl. Phys. Lett. 85, 3561 (2004).

${ }^{25}$ B. Johannessen, P. Kluth, C. J. Glover, G. de M. Azevedo, D. J. Llewellyn, G. J. Foran, and M. C. Ridgway, J. Appl. Phys. 98, 024307 (2005).

${ }^{26}$ R. Giulian, L. L. Araujo, P. Kluth, D. J. Sprouster, C. S. Schnohr, B. Johannessen, G. J. Foran, M. C. Ridgway, J. Appl. Phys. 105, 044303 (2009).

${ }^{27}$ D. J. Sprouster, R. Giulian, L. L. Araujo, P. Kluth, B. Johannessen, D. J. Cookson, G. J. Foran, J. Appl. Phys. 107, 014313 (2010).

${ }^{28}$ K. Nakagawa, M. Okamura, N. Ikenaga, T. Suzuki, and T. Kobayashi, Chem. Commun. 1998, 1025 (1998).

${ }^{29}$ R. Callec, P. N. Favennec, M. Salvi, H. L'Haridon, and M. Gauneau, Appl. Phys. Lett. 59, 1872 (1991).

${ }^{30}$ L. M. Wang and R. C. Birtcher, Philos. Mag. A 64, 1209 (1991).

${ }^{31}$ W. Wesch, C. Schnohr, P. Kluth, Z. Hussain, L. Araujo, R. Giulian, D. Sprouster, A. Byrne, and M. C. Ridgway, J. Phys. D: Appl. Phys. 42, 115402 (2009). 